\title{
Benefits of Pharmacogenetics in the Management of Hypertension
}

\section{Clara Torrellas $^{1 *}$, Juan Carlos Carril ${ }^{1}$ and Ramón Cacabelos ${ }^{2 *}$}

${ }^{1}$ EuroEspes Biomedical Research Center, Insitute for CNS Disorders, Corunna, Spain

${ }^{2}$ Chair of Genomic Medicine, Camilo José Cela University, Madrid, Spain

\begin{abstract}
Introduction: Hypertension, suffered by $35 \%$ of the population, stands out as the main risk factor for cardiovascular disorders with the highest death rate worldwide. Only a small number of patients with hypertension gets efficient control over blood pressure (BP) with appropriate drug therapy. Pharmacogenetics, as a tool to identify antihypertensive therapeutic response-associated polymorphisms, could help to reduce this problem.
\end{abstract}

Objectives: We present here an epidemiological study of the prevalence of hypertension and its pharmacological treatment to demonstrate the error rate that physicians can commit when the patient's pharmacogenetic profile is unknown.

Method: The sample consisted of 1115 individuals of which 332 met criteria for hypertension. We recorded each patient's drug prescription prior to their visit to EuroEspes Biomedical Research Center, and analyzed their pharmacogenetic profile.

Results: About $30 \%$ of patients were hypertensive, of whom only $40.4 \%$ were receiving an active ingredient for hypertension control. Among them, CYP3A4/5 and CYP2C9 were the major metabolizing enzymes. Antagonists of angiotensin II receptors, followed by calcium-blocking agents and beta-adrenergic antagonists were the most commonly-prescribed drug categories. However, $61 \%$ of hypertensive patients were not taking suitable antihypertensive agents for their metabolism according to their genetic idiosyncrasy. Furthermore, the highest error rate was determined for CYP2C9.

Conclusion: The introduction of changes in the management of hypertension in the Spanish population could be useful to promote the prevention and treatment of high blood pressure in a more efficient way. The integration of pharmacogenetic testing into routine clinical procedures could optimize the therapeutic response, guiding the physician in the choice of the correct antihypertensive drug and the correct dose. The control of BP arises as an area of particular interest in assessing the validity and utility of pharmacogenetic testing/intervention.

Keywords: Hypertension; Antihypertensive drugs; Pharmacogenetics; Prescribing errors; Cytochrome P450

Abbreviations: AIIRA: Angiotensin-II Receptor Antagonists; ACEIs: Angiotensin-Converting Enzyme Inhibitors; AHT: Arterial Hypertension; BMI: Body Mass Index; BP: Blood Pressure; CIBE: EuroEspes Biomedical Research Center; IDH: Isolated Diastolic Hypertension; ISH: Isolated Systolic Hypertension

\section{Introduction}

The increase in heart disease, which has now taken the lead among the pathologies with the greatest morbidity-mortality on an international level [1] has made the search for solutions to minimize its risk factors a matter of the highest priority. Among these, arterial hypertension (AHT) is considered to be one of the health conditions which increase to a greater extent the probability of suffering an acute cardiovascular event [2]. High blood pressure is present in approximately $69 \%$ of patients with a first myocardial infarction, in nearly $77 \%$ of patients with a first stroke, in approximately $74 \%$ of patients with congestive heart failure [3], and it is responsible for one in six deaths, with one in three adults suffering from hypertension [4]. Although over the last years there has been in high-income countries an increase in insight, and attempts to regulate this disorder, healthcare is still far from reaching optimal levels in this area [5,6], given the high worldwide prevalence which, even in this type of population where the frequency is lower, reaches $35 \%$ [7]. More specifically, the data obtained by the United States National Health and Nutrition Examination Survey (NHANES), carried out between 2009 and 2010 by the National Center for Health Statistics, revealed that approximately $30 \%$ of the American population suffered arterial hypertension, of whom only
81.9\% were aware of their condition, $76.4 \%$ were following related pharmacological treatment, and only $53.3 \%$ of cases were achieving adequate control of the same [8]. The high prevalence of undiagnosed and uncontrolled hypertension makes its therapeutic approach a medical challenge, enhanced by the scarcity and inspecificity of the clinical manifestations of AHT (which have conferred the name of "silent killer" on this disorder), the customary absence of complete efficacy of the pharmacotherapy employed for its control $[9,10]$, and lack of adherence due to the possible adverse reactions to the active ingredients employed [11].

This alarming situation, linked to a great extent with the pharmacological treatment of this disorder of a habitually chronic nature, augments the need to take caution to extremes when prescribing antihypertensives, and encouraging strict adjustment to prescriptive

*Corresponding author: Clara Torrellas, EuroEspes Biomedical Research Center, Institute of Medical Science and Genomic Medicine 15165-Bergondo, Corunna, Spain, Tel: +34-981-780505; E-mail: neuropsicologia2@euroespes.com

Ramón Cacabelos, Chair of Genomic Medicine, Camilo José Cela University, 28692 Madrid, Spain, Tel: +34-918-153131; E-mail: rcacabelos@ucjc.edu

Received February 20, 2014; Accepted March 17, 2014; Published March 25 , 2014

Citation: Torrellas C, Carril JC, Cacabelos R (2014) Benefits of Pharmacogenetics in the Management of Hypertension. J Pharmacogenomics Pharmacoproteomics 5: 126. doi:10.4172/2153-0645.1000126

Copyright: (c) 2014 Torrellas C, et al. This is an open-access article distributed under the terms of the Creative Commons Attribution License, which permits unrestricted use, distribution, and reproduction in any medium, provided the original author and source are credited. 
quality criteria. The construct "appropriateness prescription" has been defined as a pharmacological pattern which is rational, evidence-based, complete, and able to improve the health outcomes of the patient treated [12]. Some of the foremost markers of prescriptive quality are as follows: (a) The suitability of the choice of active ingredient, dosage, frequency, route of administration and duration of the treatment, (b) the strict consideration of possible drug interactions and adverse reactions, and (c) the avoidance of duplication of unnecessary medicines [12-15], non-compliance with these representing a possible serious risk for the safety, well-being and daily performance of the patients [16]. However, there exists empirical evidence of a considerable occurrence of error/unsuitability in the prescription of drugs in general, and of antihypertensives in particular [17-19]. Al Khaja et al. [20] performed a retrospective study in which they examined 2773 prescriptions of cardiovascular and antidiabetic agents issued in 20 health centers in Bahrain, and found that around $26 \%$ of the pharmacological patterns prescribed did not fulfill some criterion of prescriptive quality. The most common errors consisted of the prescription of multiple antihypertensives with a similar mechanism of action, and the choice of unsuitable dosage. Likewise, epidemiological studies performed among various populations revealed a considerable incidence of adverse effects related to the taking of antihypertensives $[21,22]$ and a considerable interindividual heterogeneity in the efficacy of these drugs $[23,24]$.

In this context, there arises a need to introduce changes in the approach to AHT, directed toward the adoption of models embracing, in addition to the arterial pressure values, a greater number of factors of a different nature (psychological, behavioral, physiological, genetic...) which are involved not only in our susceptibility to the syndrome but also in the modulation of the effects of its treatment.

Pharmacogenetics, an encouraging clinical approach included within this new comprehensive paradigm, has emerged to search for heredobiological variables (generally genetic polymorphisms) as markers to predict individual response to drugs [25]. The application of pharmacogenetic knowledge to antihypertensive prescription strategies might bring about an optimization of therapeutic efficacy, based on the personalization of pharmacological treatment [26,27]. However, the complexity of hypertension and its diverse clinical profiles, and also the range of existing antihypertensive drug categories [28] make necessary the consideration of five possible ways in which the genetic polymorphism may influence drug response: (a) Through genes that are implicated in the pathogenesis of hypertension and are able to modify the effects of drugs, (b) through variations in drug-gene mechanistic interactions, (c) through polymorphisms of drug-metabolizing enzymes; (d) through genes associated with drug transporters; and (e) through pleiotropic genes involved in multifaceted cascades and metabolic reactions [29]. Of all these sources of genetic variations with influence on the reaction to drugs, the typical pharmacogenetic investigation has been focused on the analysis of genes encoding enzymes responsible for Phase I and Phase II reactions in drug metabolism, especially genes of the cytochrome P450 (CYP) family [29-31]. Thus, knowledge of these genes has progressed at a spectacular pace over the last 25 years, achieving an extensive characterization of their allelic variants and increased identification of the specific isoforms involved in drug metabolism [32,33], which endows this superfamily with potential clinical relevance. Several first-line antihypertensive drugs, including calcium channel blockers, $\beta$-adrenergic blockers, angiotensin-II receptor blockers, angiotensin- converting enzyme inhibitors and diuretics, undergo metabolism through different CYP isoforms [34-37], especially by the isoenzymes CYP2D6, CYP2C9, CYP2C19 and CYP3A4/5, which are the most significant in the patient's response to the drug [37,38] (Table 1).

Along these lines, it is hoped that routine consideration in clinical practice of the existing knowledge of the phenotypes underlying enzyme activity which play a critical role in the metabolism of antihypertensives, together with a conscientious effort in the search for and the complete identification of other genetic polymorphisms responsible for part of the variability in response to these agents, will provide a trustworthy tool to guide the physician in the choice of active ingredients and optimal dosage, thus reducing ostensibly the problems encountered at present regarding the pharmacological safety and therapeutic inefficacy of AHT.

However, although there have been significant breakthroughs in cardiovascular pharmacogenetic research in general [37-39] and in the metabolism of antihypertensives in particular [32,36], which hint at the preventive and predictive potential of personalized pharmacotherapy, the current state of clinical research and implementation is still in a preliminary stage [40]. In view of this, the need arises to carry out exploratory studies to direct us toward the areas where the robust assessment of the viability of pharmacogenetic profiles as therapeutic guidelines is a high priority.

\begin{tabular}{|l|c|c|c|c|c|}
\hline & CYP2C9 & CYP2C19 & CYP2D6 & CYP3A4/5 & Other CYP-route \\
\hline Amlodipine & & & & + & \\
\hline Betaxolol & & & + & & + \\
\hline Bisoprolol & & & + & + & + \\
\hline Candesartan & + & & & & + \\
\hline Captopril & & & + & & + \\
\hline Carvedilol & + & + & + & + & + \\
\hline Chlorothiazide & & & & & + \\
\hline Diltiazem & + & & + & + & + \\
\hline Doxazosin & & + & + & + & + \\
\hline Enalapril & & & & + & + \\
\hline Eplerenone & & & & + & + \\
\hline Felodipine & & & & + & + \\
\hline Guanabenz & & & & & + \\
\hline Hydrochlorothia- & & & & & + \\
\hline zide & & & & + & + \\
\hline Indapamide & & & & + & + \\
\hline Irbesartan & + & & & + & + \\
\hline Isradipine & & & & + & + \\
\hline Losartan & + & + & & + & + \\
\hline Nebivolol & & & + & + & + \\
\hline Nicardipine & + & & + & + & + \\
\hline Nifedipine & & & + & + & + \\
\hline Nimodipine & & & & + & + \\
\hline Nisoldipine & & & & + & + \\
\hline Olmesartan & + & & & + & + \\
\hline Propranolol & + & + & + & + & + \\
\hline Quinapril & & & & + & + \\
\hline Ramipril & & & & + & + \\
\hline Timolol & & & & + & + \\
\hline Torsemide & & & & + & + \\
\hline Tabartan & & & & + & + \\
\hline
\end{tabular}

Table 1: Antihypertensive drugs substrates of CYP2C9, CYP2C19, CYP2D6 CYP3A4/5 [35]. 


\section{Aims}

Given the alarming figures depicted in the international bibliography regarding the detection and appropriate control of AHT, we undertook, as the general aim of this research, the analysis of the pharmacoepidemiology of the patient population suffering this pathology and attending the EuroEspes Biomedical Research Center (CIBE), an institution specializing in Genomic Medicine and Pharmacogenomics, in an attempt to present an updated panorama of AHT pharmacotherapy in Spain, as well as quantifying the incidence of sub-optimal pharmacological treatments for AHT caused by prescriptive models based solely on clinical signs. With this approach, and with no intention of establishing causal inferences, we sought to substantiate the magnitude of the potential impact that knowledge of the pharmacogenetic profile for antihypertensive metabolism might have on prescription of the same.

Specifically, we established the following aims: (a) to identify the prevalence of AHT in the population of newly-attending patients of the CIBE over the last years, (b) to detect the percentage of untreated AHT cases attending the Center, (c) to discover the pharmacological prescription pattern for AHT in the Spanish population over the last years, and (d) to assess the error rate in the patterns of antihypertensive use caused by unawareness of the patients' pharmacogenetic profiles.

\section{Participants and Method}

The population studied was comprised of 1115 patients who visited the CIBE between 2008 and 2012. From this total, a sample of 332 patients was selected by discretional sampling based on diagnostic criteria for AHT. In an attempt to avoid possible false negatives, on the basis of the demographic and also clinical heterogeneity of the patients included in the study, as well as the extensive experience of this Medical Center in the assessment of AHT in this patient profile, it was decided to apply a slightly stricter cut-off point than the standard proposed by the principal international guides for the treatment of AHT. Hypertensive patients were defined as those over 30 years of age and with a systolic $\mathrm{BP}>150 \mathrm{mmHg}$ and/or diastolic $\mathrm{BP}>85 \mathrm{mmHg}$.

As a part of the clinical interview, the pharmacological pattern prescribed for each patient prior to their visit to the CIBE was noted, and as part of the medical protocol, variations in DNA sequences corresponding to four monooxygenases (CYP2D6, CYP2C19, CYP2C9 and CYP3A4/5) were analyzed so as to identify the phenotypic profile of each individual in drug metabolism (UM: ultra-rapid metabolizers; EM: extensive metabolizers; IM: intermediate metabolizers; PM: poor metabolizers). The decision to analyze these particular isoenzymes was based on their involvement in the metabolism of the 200 currently most-prescribed drugs; first-choice antihypertensives being among these $[41,42]$, and a greater clinical implementation of the analysis of these genetic variants in the population studied. DNA was extracted from peripheral blood mononuclear cells and $25 \mathrm{ng}$ of genomic DNA from each subject was used for each multiplex SNP genotyping assay. The SNP markers were genotyped by allele-specific amplification, using TaqMan ${ }^{\circledR}$ probes anchored in OpenArray ${ }^{\mathbb{B}}$ DNA microarrays and realtime detection of the binding by fluorescence (RT-PCR).

On this basis, any prescription for antihypertensives metabolized by genes with anomalous alleles was considered to be unsuitable; that is, the prescription of an active ingredient for a particular patient whose phenotype of the gene undertaking the metabolism of said drug was categorized as UM, IM or PM, was considered to be an error.

On the basis of this information a database was generated, processed by the SPSS 16.0 software, with which a calculation was made of the frequencies and percentages of the different variables analyzed in our study.

\section{Results}

Of the initial population, consisting of 1115 patients with an average age of 48 years (SD: 21), and with similar gender-related proportions ( $48.9 \%$ women and $51.1 \%$ men), $29.76 \%$ of the individuals fulfilled the criteria proposed for the diagnosis of AHT. This subsample of hypertensive patients presented an average age of 65 years (SD: 13.27), a slight predominance of the female gender (54.5\%) over the male (45.5\%), and a high body mass index (BMI), with an average figure of $29 \mathrm{~kg} / \mathrm{m}^{2}, 83.2 \%$ of these patients being in the category of overweightness, of whom $35.2 \%$ reached the category of obesity.

The description of the pharmacogenomic characteristics analyzed in the sample with AHT is portrayed in Figure 1. Of note is a smaller proportion of normal-metabolizer phenotypes associated with the CYP2D6 and CYP2C9 genes, with figures of 55.4\% and $60.4 \%$ respectively, compared with the distribution of non-anomalous allelic frequencies in CYP2C19 (EM: 74.9\%) and CYP3A4/5 (EM: 79.56\%).

Of the total of the hypertensive population studied, only $40.4 \%$ were undergoing treatment to control AHT prior to their visit to the CIBE. The group of untreated patients presented an average Systolic $\mathrm{BP}$ value of $152.7 \mathrm{mmHg}$ (SD: 16.9) and an average Diastolic BP value of $88.01 \mathrm{mmHg}$ (SD: 9.5); Isolated Systolic Hypertension (ISH) was found in $22.7 \%$ of cases, and Isolated Diastolic Hypertension (IDH) was found in $39.9 \%$ of cases.

Among the pharmacological categories most commonly prescribed in case studies (Table 2) we find principally angiotensin-II receptor antagonists (AIIRA), followed by calcium channel blocking agents and $\beta$-adrenergic antagonists. In combined pharmacological treatment, of note is the association of any of the active ingredients of the main therapeutic groups with the diuretic hydrochlorothiazide, particularly their combination with beta-blockers. However, a prevalence of monotherapy $(77.3 \%)$, compared with polypharmacy $(21.3 \%)$ was observed in antihypertensive prescription practice.

The study of the enzymatic metabolization routes of each of the drugs prescribed in our sample showed that $78.95 \%$ of the active ingredients prescribed were metabolized via the principal genes of the CYP family, CYP2C9 and CYP3A4/5 being of particular significance (Figure 2).

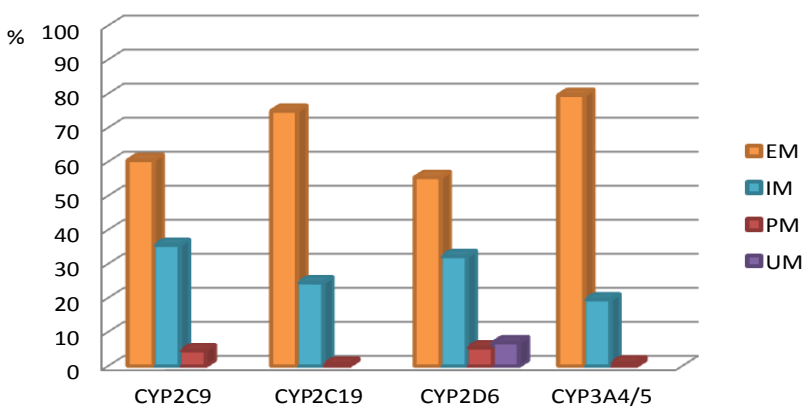

Figure 1: Distribution of metabolizer phenotype associated with CYP polymorphic variants in the studied population. 


\begin{tabular}{|c|c|c|c|}
\hline Monotherapy & $\mathbf{N}$ & $\%$ & Most frequently-prescribed drugs \\
\hline Angiotensin-II receptor antagonists & 38 & 23.46 & Losartan (13), Valsartan (8) \\
\hline Calcium channel blockers & 32 & 19.75 & Amlodipine (15), Diltiazem (8) \\
\hline$\beta$-Adrenergic receptor antagonists & 31 & 19.14 & Bisoprolol (13), Atenolol (8) \\
\hline Angiotensin-converting enzyme inhibitors & 25 & 15.43 & Enalapril (15) \\
\hline Diuretics & 19 & 12.96 & $\begin{array}{l}\text { Loop diuretics: Furosemide (6), Torsemide (5); } \\
\text { Thiazides: Indapamide (5) }\end{array}$ \\
\hline $\begin{array}{c}\text { Other categories: Vasodilators, } \alpha \text {-Adrenergic antagonists, Mixed adrenergic } \\
\text { antagonists, Centrally-acting drugs }\end{array}$ & 15 & 9.26 & $\begin{array}{l}\text { Vasodilators: Minidoxil (1); } \\
\text { a-Adrenergic antagonists: Doxazosin mesylate (7); } \\
\text { Mixed adrenergic antagonists: Carvedilol (4); }\end{array}$ \\
\hline Drug Combinations & $\mathbf{N}$ & $\%$ & Most frequently-prescribed drugs \\
\hline Angiotensin-II receptor antagonists + Diuretics & 29 & 61.70 & $\begin{array}{l}\text { Combinations with Hydrochlorothiazide: } \\
\text { Valsartan + Hydrochlorothiazide (9); } \\
\text { Irbesartan + Hydrochlorothiazide (6) }\end{array}$ \\
\hline Angiotensin-converting enzyme inhibitors + Diuretics & 7 & 14.89 & Enalapril + Hydrochlorothiazide (4) \\
\hline Diuretic combinations & 5 & 10.64 & Amiloride + Hydrochlorothiazide (4) \\
\hline Calcium channel blockers + Angiotensin-II receptor antagonists & 2 & 4.26 & \\
\hline$\beta$-Adrenergic receptor antagonists + Diuretics & 2 & 4.26 & \\
\hline Calcium channel blockers + Statins & 1 & 2.13 & \\
\hline Calcium channel blockers $+\beta$-Adrenergic receptor antagonists & 1 & 2.13 & \\
\hline
\end{tabular}

Table 2: Trends in hypertension management in Spanish population.

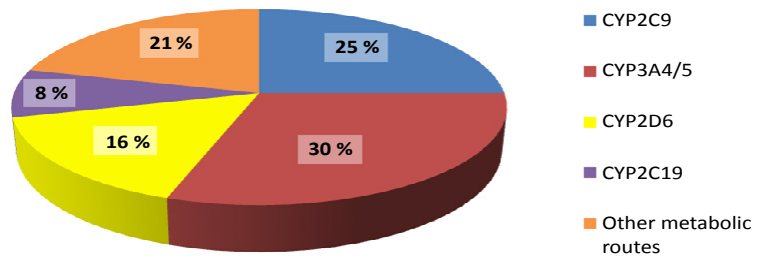

Figure 2: Antihypertensive agents metabolized via enzymes of the CYP gene family.

Furthermore, taking into account only the pharmacogenetic analysis of those hypertensive patients with prior treatment of drugs metabolized by one of the principal CYP genes, and excluding the enzymatic transformations carried out by other genetic pathways, a significant error rate of $61.21 \%$ was discovered in pharmacological patterns established by the traditional trial-and-error method (Figure 3).

The distribution of said error according to each of the CYP genes examined may be seen in Figure 4.

\section{Discussion}

Our investigation revealed a high prevalence of AHT in the Spanish population, reaching almost $30 \%$ of participants over 30 years of age. Similar results appear repeatedly in publications on the epidemiology of this pathology in Spain [43-45] and in other developed countries [46]. However, the alarming magnitude of this problem is not exclusively limited to the frequency of the appearance of this syndrome but, among other aspects, the high regularity with which the disorder remains undetected or simply is not pharmacologically treated. Therapeutic analysis of the sample analyzed revealed that almost $60 \%$ of patients with AHT were not taking any treatment to lower their blood pressure (BP). Prior nationwide studies described more favorable ratios in the use of pharmacotherapy [44,47], probably explained by the consideration of a higher threshold for the detection of AHT. However, in any case it is fitting to mention that a slight reduction in pharmacological infra-management of AHT has been experienced over the last decade [45], favored by a greater familiarity with and consciousness of the problem within the healthcare sector, a result of, among other aspects, new health policies implemented in developed countries, and the greater evidence of clinical efficacy of the active ingredients available [7]. However, the figures obtained are still far from the desired results depending upon different approaches to ATH treatment [48-50]. This might explain the absence of pharmacological indications for controlling a significant number of patients with high diastolic BP values. Notwithstanding, given that IDH conditions frequently evolve into systolic-diastolic hypertension and into secondary types of hypertension, as well as presenting a high risk of future cardiovascular complications and diabetes [51], it is important to undertake clinical intervention in order to control this hypertension subtype as a measure to reduce cardiovascular morbidity and mortality [52].

Notwithstanding the recommendations of the principal international guides for the management of AHT [53,54], which suggest the use of combinations of antihypertensives to control BP, the present study portrays a significant advantage in the choice of monopharmacy in prescription patterns in the Spanish population. The prescription of active ingredients of the angiotensin-II receptor antagonist, calcium channel antagonist and beta-adrenergic antagonist categories is of particular note. This tendency in the prescription of antihypertensives shares similarities with the pattern found in research performed on other Spanish populations over the last years $[55,56]$ where drugs acting upon the renin-angiotensin axis, of more recent vintage, surpass the prescription of the classic groups (diuretics in particular). The predominance of AIIRAs over angiotensin-converting enzyme inhibitors (ACEIs) might be due to the evidence of greater tolerability of said substances [57].

The comparative studies performed at a population level and which were presented in the latest guide published by the European Society of Hypertension and the European Society of Cardiology [54], do not reflect the significant differences between the principal antihypertensive drug categories; these do become apparent in individualized clinical practice. This dissociation might be reflective of how genetic polymorphisms associated with drug metabolism, among other groups of genes involved, affect the efficacy of these drugs and the manifestation of side-effects of the same. In this regard, the examination of the distribution of the polymorphic variants of the four genes of the CYP family in the sample of patients with AHT revealed 


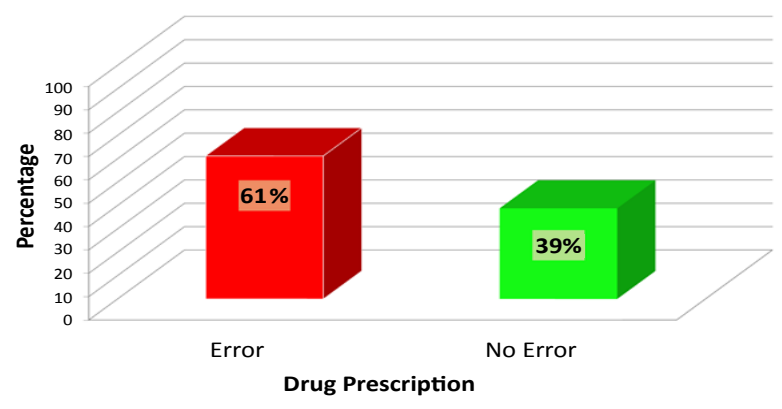

Figure 3: Error rate in antihypertensive drug prescription in Spanish patients with unknown pharmacogenetic profiles.

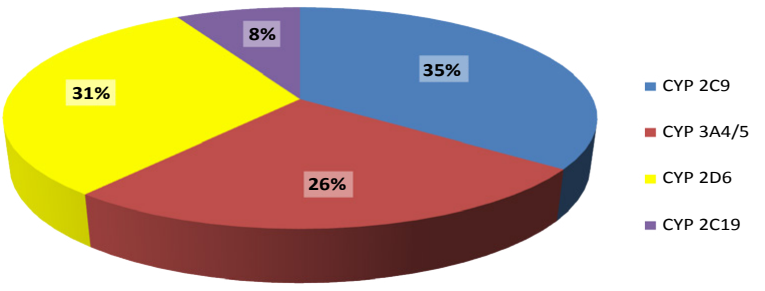

Figure 4: Error rate in antihypertensive drug prescription in patients by CYP profile.

a noteworthy heterogeneity in their drug-metabolizing phenotypes, the greatest incidence of normal enzyme activity being found in the biotransformation pathways belonging to the CYP3A4/5 (80\%) and CYP2C19 (75\%) genes, followed by that of the CYP2C9 gene (60\%) and finally that of the CYP2D6 gene (55\%). This pattern, found in the clinical population, is compatible with some of the allelic frequencies known in the Spanish population in general (in particular those associated with CYP2C9 and CYP2D6, where the distribution is practically equivalent) $[29,38]$. If we confine ourselves exclusively to the role played by the isoenzymes analyzed in the phase I reactions in the metabolism of hypertensives, we might anticipate a greater probability of therapeutic inefficacy if an antihypertensive metabolized via the CYP2D6 and CYP2C9 pathways is administered.

Continuing along these lines, it is interesting to discover which enzymatic pathway is followed by the most important active ingredients in AHT treatment during metabolization. Thus, investigation of the active ingredients which act as major substrates of some of the CYP genes analyzed revealed a greater proportion of hepatic biotransformation via the CYP3A4/5 gene pathway, followed by the route corresponding to the $\mathrm{CYP} 2 \mathrm{C} 9$ gene. Therefore, given the extensive number of antihypertensives which use this last metabolic pathway, which besides presents mutations in an appreciable percentage of the population, it is not difficult to infer that this is the type of drug which may present the most therapeutic inefficacy in the sample analyzed, thus explaining the greater concentration of prescriptive error in the metabolization pathway corresponding to the CYP2C9 gene. Likewise, in spite of taking part in the metabolization of a small number of the active ingredients analyzed, the enzymatic pathway associated with CYP2D6 accrued almost the same percentage of error as the former, given the high variation in allelic frequencies found in the sample.

Finally, regarding the central theme of our research, which promotes the consideration of the analysis of CYP450 activity for the hypertensive population as a whole, we may highlight the existence of an error rate of $61 \%$ in the pharmacological pattern of antihypertensives when the classic prescriptive criteria of trial-and-error are followed. These figures are consistent with those of epidemiological studies which explore the success achieved in the control of BP in patients with correct adherence to the pharmacotherapy prescribed, obtaining normalization in BP levels in a range of only $30-60 \%$ of cases [58-60]. One of the possible causes of the poor benefits obtained might be rooted in the unawareness of the majority of physicians regarding the interindividual variability in response to antihypertensives according to the different metabolizing phenotypes presented by AHT patients [61]. In the extensive literature review carried out, we found no studies performed on other populations to enable us to compare the proportion of antihypertensives which were sub-optimally metabolized due to the involvement of these four isoenzymes under study. However, studies do exist which without taking the pharmacogenetic profile into account, and based solely on clinical and technical criteria, reflect a significant number of potentially inappropriate prescriptions concerning these pharmacological categories [62-65]. Thus, we put forward that adding a new source of error based on drug metabolism-associated genetic variants represents an escalation of the problem, but it also opens a new field to be considered amongst the policies directed toward the reduction of medical errors.

\section{Limitations and Future Research Perspectives}

The findings in this report are subject to at least four limitations. Firstly, it must be taken into account that the period of antihypertensive intake was not homogenized, this possibly being a source of bias in the calculation of the therapeutic efficacy of the drugs prescribed. Secondly, the cross-sectional study design provides a one-timeonly assessment of blood pressure, and this could overestimate or underestimate hypertension prevalence. On the other hand, this study is limited to the advantages which the identification of alleles corresponding to a limited number of genes involved in the metabolism of a large proportion of antihypertensive drugs might provide for the control of AHT. However, there are other candidate genes of blood pressure response to antihypertensive drug therapy, which might be associated with both the pharmacodynamics and the pharmacokinetics of said compounds. Thus, the results collected with a solely descriptive nature merely indicate the existence of a sub-optimal approach to AHT of a considerable magnitude, which highlights the implications of the future implementation of inferential studies which verify the potential causal nature of the polymorphisms involved in the metabolism of antihypertensives in the interindividual variation in their therapeutic efficacy. Additionally, as a future field of research, we suggest the exploration of the possible clinical relevance of knowledge of the functionality of allelic variants of other genes which have shown association or interactions with the response to BP medications. From this perspective, studies of great scientific significance $[40,66]$ have suggested the possible involvement of renin-angiotensinaldosterone system genes (ACE, AGT, AGTR1, AGTR2, CYP11B2, REN), sympathetic nervous system/vascular tone genes (ADRB2), ion transport and fluid balance genes (ADD), among those of greatest significance. Finally, the calculation of the ratios of uncontrolled hypertension in the epidemiological design carried out did not allow for the impact of factors of a behavioral (e.g. exercise, diet) or physiological (e.g. salt sensitivity) nature, whose correlation with AHT is proven $[67,68]$; nor was its interaction with pharmacogenetic variables taken into account. Thus, making future studies more complex by including the analysis of the influx of this type of variables might provide a broader perspective of this clinical condition and its integral treatment. 
Citation: Torrellas C, Carril JC, Cacabelos R (2014) Benefits of Pharmacogenetics in the Management of Hypertension. J Pharmacogenomics Pharmacoproteomics 5: 126. doi:10.4172/2153-0645.1000126

Page 6 of 7

\section{Conclusions}

In view of these results, the need to introduce changes in the management of AHT, defending the prevention and control of the same from a more effective viewpoint, seems obvious. Prioritizing the importance of this pathology, and replacing the habitual empiricallybased prescriptive framework with treatment contemplating the pharmacogenetic profile of the patient, might provide incalculable advantages for the health of that great percentage of patients with AHT, and also a significant reduction in the economic costs currently borne by the healthcare system $[23,27]$. However, in spite of these promising prospects, it is necessary to enter into more detail in the exploration of the clinical usefulness of pharmacogenetic testing, as the routine implementation of the same depends largely on obtaining robust evidence of its added value in comparison with care-as-usual.

\section{References}

1. Barber N, Rawlins M, Dean Franklin B (2003) Reducing prescribing error competence, control, and culture. Qual Saf Health Care 12: i29-32.

2. Kearney PM, Whelton M, Reynolds K, Muntner P, Whelton PK, et al. (2005) Global burden of hypertension: analysis of worldwide data. Lancet 365: 217-223.

3. Lloyd-Jones D, Adams R, Carnethon M, De Simone G, Ferguson TB, et al. (2009) Heart disease and stroke statistics--2009 update: a report from the American Heart Association Statistics Committee and Stroke Statistics Subcommittee. Circulation 119: e21-181.

4. Olives C, Myerson R, Mokdad AH, Murray CJ, Lim SS (2013) Prevalence, awareness, treatment, and control of hypertension in United States counties, 2001-2009. PLoS One 8: e60308.

5. Egan BM, Zhao Y, Axon RN (2010) US trends in prevalence, awareness, treatment, and control of hypertension, 1988-2008. JAMA 303: 2043-2050.

6. Banegas JR, Segura J, Ruilope LM, Luque M, García-Robles R, et al. (2004) Blood pressure control and physician management of hypertension in hospital hypertension units in Spain. Hypertension 43: 1338-1344.

7. World Health Organization (2011) Global status report on noncommunicable diseases 2010. World Health Organization, Geneva.

8. Yoon SS, Burt V, Louis T, Carroll MD (2012) Hypertension among adults in the United States, 2009-2010. NCHS Data Brief: 1-8.

9. Thoenes M, Neuberger HR, Volpe M, Khan BV, Kirch W, et al. (2010) Antihypertensive drug therapy and blood pressure control in men and women: an international perspective. J Hum Hypertens 24: 336-344.

10. Diao D, Wright JM, Cundiff DK, Gueyffier F (2012) Pharmacotherapy for mild hypertension. Cochrane Database Syst Rev 8: CD006742.

11. Elliott WJ (2009) Improving outcomes in hypertensive patients: focus on adherence and persistence with antihypertensive therapy. J Clin Hypertens (Greenwich) 11: 376-382

12. Hassan NB, Ismail HC, Naing L, Conroy RM, Abdul Rahman AR (2010) Development and validation of a new Prescription Quality Index. $\mathrm{Br} \mathrm{J}$ Clin Pharmacol 70: 500-513.

13. Laing R, Hogerzeil $H$, Ross-Degnan D (2001) Ten recommendations to improve use of medicines in developing countries. Health Policy Plan 16: 13-20.

14. Majeed A, Lester $H$, Bindman $A B$ (2007) Improving the quality of care with performance indicators. BMJ 335: 916-918.

15. Alyamani NA, Hopf Y, Williams DJ (2009) Prescription quality in an acute medical ward. Pharmacoepidemiol Drug Saf 18: 1158-1165

16. Dean B, Schachter M, Vincent C, Barber N (2002) Prescribing errors in hospital inpatients: their incidence and clinical significance. Qual Saf Health Care 11: 340-344.

17. Lewis PJ, Dornan T, Taylor D, Tully MP, Wass V, et al. (2009) Prevalence, incidence and nature of prescribing errors in hospital inpatients: a systematic review. Drug Saf 32: 379-389.

18. Hamano J, Tokuda $Y(2014)$ Inappropriate prescribing among elderly home care patients in Japan: prevalence and risk factors. J Prim Care Community Health 5: 90-96.

19. Alshaikh M, Mayet A, Aljadhey $H$ (2013) Medication error reporting in a university teaching hospital in Saudi Arabia. J Patient Saf 9: 145-149.

20. Al Khaja KA, Sequeira RP, Damanhori AH (2012) Medication prescribing errors pertaining to cardiovascular/antidiabetic medications: a prescription audit in primary care. Fundam Clin Pharmacol 26: 410-417.

21. Svensson S, Kjellgren KI (2003) Adverse events and patients' perceptions of antihypertensive drug effectiveness. J Hum Hypertens 17: 671-675.

22. Bardage C, Isacson DG (2000) Self-reported side-effects of antihypertensive drugs: an epidemiological study on prevalence and impact on health-state utility. Blood Press 9: 328-334.

23. Materson BJ (2007) Variability in response to antihypertensive drugs. Am J Med 120: S10-20.

24. Polimanti R, lorio A, Piacentini S, Manfellotto D, Fuciarelli M (2014) Human pharmacogenomic variation of antihypertensive drugs: from population genetics to personalized medicine. Pharmacogenomics 15: 157-167.

25. Lindpaintner K (2003) Pharmacogenetics and the future of medical practice. $J$ Mol Med (Berl) 81: 141-153.

26. Brown MJ (2011) Personalised medicine for hypertension. BMJ 343:d4697.

27. Israili ZH, Hernández-Hernández R, Valasco M (2007) The future of antihypertensive treatment. Am J Ther 14: 121-134.

28. Arnett DK, Claas SA, Lynch Al (2009) Has pharmacogenetics brought us close to 'personalized medicine' for initial drug treatment of hypertension? Curr Opin Cardiol 24: 333-339.

29. Cacabelos R (2012) The Metabolomic Paradigm of Pharmacogenomics in Complex Disorders. Metabolomics 2: e119.

30. Schwartz GL, Turner ST (2004) Pharmacogenetics of antihypertensive drug responses. Am J Pharmacogenomics 4: 151-160.

31. Kirchheiner J, Seeringer A (2007) Clinical implications of pharmacogenetics of cytochrome P450 drug metabolizing enzymes. Biochim Biophys Acta 1770: 489-494.

32. Flockhart DA, Tanus-Santos JE (2002) Implications of cytochrome P450 interactions when prescribing medication for hypertension. Arch Intern Med 162: 405-412.

33. Ingelman-Sundberg M (2004) Pharmacogenetics of cytochrome P450 and its applications in drug therapy: the past, present and future. Trends Pharmacol Sci 25: 193-200.

34. Kreutz R (2004) Pharmacogenetics of antihypertensive drug response. Curr Hypertens Rep 6: 15-20.

35. Cacabelos R (Ed) (2012) World guide for drug use and pharmacogenomics. EuroEspes Publishing, Corunna.

36. Höcht C, Bertera FM, Mayer MA, Taira CA (2010) Issues in drug metabolism of major antihypertensive drugs: beta-blockers, calcium channel antagonists and angiotensin receptor blockers. Expert Opin Drug Metab Toxicol 6(2):199-211.

37. Siest G, Jeannesson E, Visvikis-Siest S (2007) Enzymes and pharmacogenetics of cardiovascular drugs. Clin Chim Acta 381: 26-31.

38. Rodríguez Arcas MJ, García-Jiménez E, Martínez-Martínez F, Conesa-Zamora $P$ (2011) Role of CYP450 in pharmacokinetics and pharmacogenetics of antihypertensive drugs. Farm Hosp 35: 84-92.

39. Ong FS, Deignan JL, Kuo JZ, Bernstein KE, Rotter JI, et al. (2012) Clinical utility of pharmacogenetic biomarkers in cardiovascular therapeutics: a challenge for clinical implementation. Pharmacogenomics 13:465-475.

40. Brugts JJ, de Maat MP, Boersma E, Witteman JC, van Duijn C, et al. (2009) The rationale and design of the PERindopril GENEtic association study (PERGENE): a pharmacogenetic analysis of angiotensin-converting enzyme inhibitor therapy in patients with stable coronary artery disease. Cardiovasc Drugs Ther 23:171-181.

41. Zhong HA, Mashinson V, Woolman TA, Zha M (2013) Understanding the molecular properties and metabolism of top prescribed drugs. Curr Top Med Chem 13: 1290-1307.

42. Preissner SC, Hoffmann MF, Preissner R, Dunkel M, Gewiess A, et al. (2013) 
Citation: Torrellas C, Carril JC, Cacabelos R (2014) Benefits of Pharmacogenetics in the Management of Hypertension. J Pharmacogenomics Pharmacoproteomics 5: 126. doi:10.4172/2153-0645.1000126

Polymorphic cytochrome P450 enzymes (CYPs) and their role in personalized therapy. PLoS One 8: e82562.

43. Medrano MJ, Cerrato E, Boix R, Delgado-Rodríguez M (2005) [Cardiovascular risk factors in Spanish population: metaanalysis of cross-sectional studies]. Med Clin (Barc) 124: 606-612.

44. Perez-Fernandez R, Mariño AF, Cadarso-Suarez C, Botana MA, Tome MA, et al. (2007) Prevalence, awareness, treatment and control of hypertension in Galicia (Spain) and association with related diseases. J Hum Hypertens 21: 366-373

45. Ortiz Marrón H, Vaamonde Martín RJ, Zorrilla Torrás B, Arrieta Blanco $F$, Casado López M, et al. (2011) [Prevalence, degree of control and treatment of hypertension in the adult population of Madrid, Spain]. Rev Esp Salud Publica 85: 329-338.

46. Ikeda N, Sapienza D, Guerrero R, Aekplakorn W, Naghavi M, et al. (2014) Control of hypertension with medication: a comparative analysis of national surveys in 20 countries. Bull World Health Organ 92: 10-19C.

47. Wolf-Maier K, Cooper RS, Kramer H, Banegas JR, Giampaoli S, et al. (2004) Hypertension treatment and control in five European countries, Canada, and the United States. Hypertension 43: 10-17.

48. Hozawa A, Ohkubo T, Nagai K, Kikuya M, Matsubara M, et al. (2000) Prognosis of isolated systolic and isolated diastolic hypertension as assessed by selfmeasurement of blood pressure at home: the Ohasama study. Arch Intern Med 160: 3301-3306

49. Schillaci G, Pirro M, Mannarino E (2009) Assessing cardiovascular risk: should we discard diastolic blood pressure? Circulation 119: 210-212.

50. Leonetti G, Cuspidi C, Facchini M, Stramba-Badiale M (2000) Is systolic pressure a better target for antihypertensive treatment than diastolic pressure? J Hypertens Suppl 18: S13-20.

51. Franklin SS (2007) The importance of diastolic blood pressure in predicting cardiovascular risk. J Am Soc Hypertens 1: 82-93.

52. Musini VM, Tejani AM, Bassett K, Wright JM (2009) Pharmacotherapy for hypertension in the elderly. Cochrane Database Syst Rev: CD000028.

53. Chobanian AV, Bakris GL, Black HR, Cushman WC, Green LA. et al. (2003) Seventh Report of the Joint National Committee on prevention, Detection, Evaluation and Treatment of High Blood Pressure: the JNC 7 complete report. Hypertension 42: 1206-1252.

54. Mancia G, De Backer G, Dominiczak A, Cifkova R, Fagard R, et al. (2007) 2007 Guidelines for the Management of Arterial Hypertension: The Task Force for the Management of Arterial Hypertension of the European Society of Hypertension (ESH) and of the European Society of Cardiology (ESC). J Hypertens 25: 11051187.

55. Sanfélix-Gimeno G, Peiró S, Librero J, Grupo de Investigación en Utilización de Medicamentos en el Sistema Nacional de Salud (Grupo IUM-SNS) de la Comunidad Valenciana (2010) Variations in antihypertensive drug utilization among primary care areas in the autonomous region of Valencia (Spain). Gac Sanit 24: 397-403.
56. Ruiz JC, Ariza MA, Aguilera B, Leal M, Gómez R, et al. (2012) [Analysis of the rational use of anti-hypertensives in the Murcia (Spain) region]. Aten Primaria 44: $272-279$

57. Nickenig G, Ostergren J, Struijker-Boudier H (2006) Clinical evidence for the cardiovascular benefits of angiotensin receptor blockers. J Renin Angiotensin Aldosterone Syst 7: S1-7.

58. Llisterri JL, Rodriguez-Roca GC, Escobar C, Alonso-Moreno FJ, Prieto MA, et al. (2012) Treatment and blood pressure control in Spain during 2002-2010. J Hypertens 30: 2425-2431.

59. Kumara WA, Perera T, Dissanayake M, Ranasinghe P, Constantine GR (2013) Prevalence and risk factors for resistant hypertension among hypertensive patients from a developing country. BMC Res Notes 6: 373.

60. Catalá-López F, Sanfélix-Gimeno G, García-Torres C, Ridao M, Peiró S (2012) Control of arterial hypertension in Spain: a systematic review and metaanalysis of 76 epidemiological studies on 341632 participants. J Hypertens 30: $168-176$.

61. Arnett DK, Claas SA (2009) Pharmacogenetics of antihypertensive treatment detailing disciplinary dissonance. Pharmacogenomics 10: 1295-1307.

62. Breton G, Froissart M, Janus N, Launay-Vacher V, Berr C, et al. (2011) Inappropriate drug use and mortality in community-dwelling elderly with impaired kidney function--the Three-City population-based study. Nephrol Dial Transplant 26: 2852-2859.

63. Pinilla A, Cano N, Granados C, Paez-Canro C, Eslava-Schmalbach J (2011) Inequalities in prescription of hydrochlorothiazide for diabetic hypertensive patients in Colombia. Rev Salud Publica (Bogota) 13: 27-40.

64. Galvin R, Moriarty F, Cousins G, Cahir C, Motterlini N, et al. (2014) Prevalence of potentially inappropriate prescribing and prescribing omissions in older Irish adults: findings from The Irish LongituDinal Study on Ageing study (TILDA). Eur $\mathrm{J}$ Clin Pharmacol [Epub ahead of print].

65. Jones SA, Bhandari S (2013) The prevalence of potentially inappropriate medication prescribing in elderly patients with chronic kidney disease. Postgrad Med J 89: 247-250.

66. Arnett DK, Boerwinkle E, Davis BR, Eckfeldt J, Ford CE, et al. (2002) Pharmacogenetic approaches to hypertension therapy: design and rationale for the Genetics of Hypertension Associated Treatment (GenHAT) study. Pharmacogenomics J 2: 309-317.

67. Franco V, Oparil S (2006) Salt sensitivity, a determinant of blood pressure cardiovascular disease and survival. J Am Coll Nutr 25: 247S-255S.

68. Hu G, Barengo NC, Tuomilehto J, Lakka TA, Nissinen A, et al. (2004) Relationship of physical activity and body mass index to the risk of hypertension: a prospective study in Finland. Hypertension 43: 25-30. 